\title{
Communication \\ Influence of Phase Composition and Pretreatment on the Conversion of Iron Oxides into Iron Carbides in Syngas Atmospheres
}

\author{
Aleks Arinchtein ${ }^{1}$, , Meng-Yang Ye ${ }^{1}$, Michael Geske ${ }^{2}$, Marvin Frisch ${ }^{1}$ and Ralph Kraehnert ${ }^{1, *}$ \\ 1 Department of Chemistry, Technische Universität Berlin, Strasse des 17. Juni 124, D-10623 Berlin, Germany; \\ aleks.arinchtein@tu-berlin.de (A.A.); meng-yang.ye@tu-berlin.de (M.-Y.Y.); m.frisch@tu-berlin.de (M.F.) \\ 2 BasCat-UniCat BASF JointLab, Technische Universität Berlin, Hardenbergstraße 36, \\ D-10623 Berlin, Germany; michael.geske@tu-berlin.de \\ * Correspondence: ralph.kraehnert@tu-berlin.de; Tel.: +49-30-314-23518
}

Citation: Arinchtein, A.; Ye, M.-Y.; Geske, M.; Frisch, M.; Kraehnert, R. Influence of Phase Composition and Pretreatment on the Conversion of Iron Oxides into Iron Carbides in Syngas Atmospheres. Catalysts 2021, 11,773. https://doi.org/10.3390/ catal11070773

Academic Editor: Simone Mascotto

Received: 20 May 2021

Accepted: 24 June 2021

Published: 25 June 2021

Publisher's Note: MDPI stays neutral with regard to jurisdictional claims in published maps and institutional affiliations.

Copyright: (c) 2021 by the authors. Licensee MDPI, Basel, Switzerland. This article is an open access article distributed under the terms and conditions of the Creative Commons Attribution (CC BY) license (https:// creativecommons.org/licenses/by/ $4.0 /)$.

\begin{abstract}
CO}_{2}$ Fischer-Tropsch synthesis $\left(\mathrm{CO}_{2}-\mathrm{FTS}\right)$ is a promising technology enabling conversion of $\mathrm{CO}_{2}$ into valuable chemical feedstocks via hydrogenation. Iron-based $\mathrm{CO}_{2}-\mathrm{FTS}$ catalysts are known for their high activities and selectivities towards the formation of higher hydrocarbons. Importantly, iron carbides are the presumed active phase strongly associated with the formation of higher hydrocarbons. Yet, many factors such as reaction temperature, atmosphere, and pressure can lead to complex transformations between different oxide and/or carbide phases, which, in turn, alter selectivity. Thus, understanding the mechanism and kinetics of carbide formation remains challenging. We propose model-type iron oxide films of controlled nanostructure and phase composition as model materials to study carbide formation in syngas atmospheres. In the present work, different iron oxide precursor films with controlled phase composition (hematite, ferrihydrite, maghemite, maghemite/magnetite) and ordered mesoporosity are synthesized using the evaporation-induced self-assembly (EISA) approach. The model materials are then exposed to a controlled atmosphere of $\mathrm{CO} / \mathrm{H}_{2}$ at $300{ }^{\circ} \mathrm{C}$. Physicochemical analysis of the treated materials indicates that all oxides convert into carbides with a core-shell structure. The structure appears to consist of crystalline carbide cores surrounded by a partially oxidized carbide shell of low crystallinity. Larger crystallites in the original iron oxide result in larger carbide cores. The presented simple route for the synthesis and analysis of soft-templated iron carbide films will enable the elucidation of the dynamics of the oxide to carbide transformation in future work.
\end{abstract}

Keywords: $\mathrm{CO}_{2}$ Fischer-Tropsch synthesis; iron oxide; iron carbides; mesoporous films; EISA

\section{Introduction}

The ongoing increase in atmospheric levels of $\mathrm{CO}_{2}$ is one of the major reasons for pronounced global warming and climate change over the last decades on earth [1,2]. Thus, great efforts were recently made to develop technologies for $\mathrm{CO}_{2}$ reduction [3-5]. $\mathrm{CO}_{2}$ Fischer-Tropsch synthesis $\left(\mathrm{CO}_{2}-\mathrm{FTS}\right)$ is a promising approach to convert $\mathrm{CO}_{2}$ with hydrogen $\left(\mathrm{H}_{2}\right)$ into olefins $\left(\mathrm{C}_{2}-\mathrm{C}_{4}\right.$ alkenes), which are important feedstocks for the chemical industry $[6,7]$. The reaction has been reported to proceed in two steps: the reverse water gas shift reaction (RWGS), which reduces $\mathrm{CO}_{2}$ to $\mathrm{CO}$, and a subsequent hydrogenation of $\mathrm{CO}$, i.e., a typical CO Fischer-Tropsch synthesis (CO-FTS). Iron-based catalysts, such as hematite $\left(\alpha-\mathrm{Fe}_{2} \mathrm{O}_{3}\right)$, are able to catalyze both reactions under similar reaction conditions and show high selectivities toward higher hydrocarbons [6-8]. Therefore, it is of great importance to develop stable and highly efficient iron-based $\mathrm{CO}_{2}-\mathrm{FTS}$ catalysts.

Iron-based catalysts were shown to undergo a complex dynamic structural change during the $\mathrm{CO}_{2}-\mathrm{FTS}$ process. $\alpha-\mathrm{Fe}_{2} \mathrm{O}_{3}$, a typical starting material, can be converted under the employed reducing conditions into many different phases under the conditions of the 
$\mathrm{CO}_{2}$-FTS- such as wustite $(\mathrm{FeO})$, maghemite $\left(\gamma-\mathrm{Fe}_{2} \mathrm{O}_{3}\right)$, magnetite $\left(\mathrm{Fe}_{3} \mathrm{O}_{4}\right)$, elemental iron $(\mathrm{Fe})$, and iron carbides. Each of these phases may potentially form species which affect both activity and selectivity of the catalyst [8-11].

Previous studies indicate that iron carbides are favorable for the formation of higher hydrocarbons [12]. Schroff et al. investigated $\mathrm{Fe}_{3} \mathrm{O}_{4}$ catalysts in the $\mathrm{CO}_{2}-\mathrm{FTS}$. In their study, pristine $\mathrm{Fe}_{3} \mathrm{O}_{4}$ was observed to show hardly any catalytic activity for the CO-FTS. More importantly, the formation of a carbide phase turned out to be of pivotal importance to obtain high catalytic activities [13]. Herranz et al. used pure hematite catalysts, tracing the formation of cementite $\left(\theta-\mathrm{Fe}_{3} \mathrm{C}\right)$ and Hägg iron $\left(\chi-\mathrm{Fe}_{5} \mathrm{C}_{2}\right)$ during a pretreatment in a mixture of gaseous $\mathrm{CO} / \mathrm{H}_{2}$. Beyond that, the authors revealed the formation of carbonaceous intermediate species on the surface of Hägg iron $\left(\chi-\mathrm{Fe}_{5} \mathrm{C}_{2}\right)$ carbides, which are claimed to be more active for the $\mathrm{CO}_{2}-\mathrm{FTS}$ [9]. Moreover, Yao et al., reported the use of syngas treatments prior to $\mathrm{CO}_{2}-\mathrm{FTS}$ as an elegant way to activate the catalysts [14]. A comprehensive review on syngas-induced carbide formation, related iron oxide and carbide phases, challenges in material characterization, and deactivation mechanisms has been reported by de Smit and Weckhuysen in 2008 [11].

Additionally, the structure of the catalyst has a great impact on catalytic performance and carbide formation. Galvis et al., reported significant particle size effects for supported iron carbides [15]. Different studies focused on the addition of promotors. Alkali metals e.g., potassium were reported to enhance the catalytic performance [11,16]. Galvis et al., studied sodium and/sulfur promoted catalysts and observed increased carbide contents depending on the sodium/sulfur concentration. The results showed that not necessarily the highest carbide content results in the best performing catalyst [17].

In the recent years, sophisticated characterization techniques in the field of surface analysis led to an identification of formed iron carbide phases and other carbonaceous intermediate species on iron-based catalysts in $\mathrm{CO}_{2}-\mathrm{FTS}$ [18]. Nonetheless, understanding the carbide formation process under the $\mathrm{CO}_{2}$-FTS reaction conditions still remains a challenge. Iron oxides can show various crystal structures and different phases, which, accordingly, obstruct clear conclusions due to the heterogeneity of the studied catalysts [8,9]. Moreover, these materials are sensitive to changes in temperature, time on stream, applied pressure, humidity, gases (air, $\mathrm{H}_{2}, \mathrm{CO}, \mathrm{CO}_{2}$ ) during $\mathrm{CO}_{2}$-FTS [6-8]. Beyond that, rather low crystallinities of the intermediate phases and complex nature of the surface species on iron-based catalysts in $\mathrm{CO}_{2}$-FTS process make a clear identification of the carbide phases among other possible intermediate phases difficult. Therefore, in order to develop an efficient guideline for designing high performance iron-based $\mathrm{CO}_{2}-\mathrm{FTS}$ catalysts, a fundamental understanding for the dynamic and mechanistic behavior has to be achieved. In a first step, we investigate the formation of carbides in $\mathrm{CO} / \mathrm{H}_{2}$ mixtures, i.e., treatments that favor rapid carbide formation and can be used to activate $\mathrm{CO}_{2}-\mathrm{FTS}$ catalysts.

Herein, we introduce an approach to use model-type iron oxide films with a welldefined mesoporous structure to shed light on the formation of carbides upon exposure to synthesis gas on different length scales. Physicochemical properties were assessed by complementary bulk- and surface-sensitive analysis techniques. The mesoporous iron oxide films can be synthesized with different initial phase composition as established in our previous work, i.e., hematite [19], ferrihydrite, [19] maghemite [20] as well as a maghemite partially converted into magnetite [20]. We previously employed this approach to investigate phase transformation and crystallization behavior of iron oxides and/or oxohydroxides upon exposure to air, [19] $\mathrm{N}_{2}$, [20] $\mathrm{Ar} / \mathrm{H}_{2}$ [20] as well as the role of water [21] in oxide phase transformations.

Briefly, the model-type oxide films are prepared using the well-established EISA approach with block-copolymer micelles as soft template for the introduction of a mesoporous structure [22,23]. It enables synthesis of well-ordered mesoporous thin films with tunable composition, crystallite size and wall thickness [24,25]. The as-synthesized ordered mesoporous films enable a precise investigation of bulk-averaged information (e.g., $\mathrm{XRD}$ ) and study of local changes in the phase composition, i.e., domain growth on the 
nanometer scale using microscope methods such as SEM, TEM, and SAED. Beyond that, thin mesoporous iron oxide films can avoid the shortcomings of typical nanoparticles such as low accessibility, pronounced agglomeration or ill-defined particle shapes which were shown to cause difficulties in the studies of in situ surface reactions [14,15,26-28].

In this work, different iron oxide phases with template-controlled mesopore structure, i.e., hematite (HEM), ferrihydrite (FH), maghemite (MAGH), and maghemite/magnetite (MAGH/MAGN) were exposed to syngas and studied via different analytical methods prior and after syngas treatment to understand the phase transformation and crystallization into carbides. To the best of our knowledge no mesoporous carbide films have been reported. The developed models present a powerful tool for mechanistic studies also under conditions of the $\mathrm{CO}_{2}-\mathrm{FTS}$.

\section{Results}

The preparation of the mesoporous iron oxide films via the EISA approach is outlined in Scheme 1, including the syngas treatment applied to the precursor films in the right column. Typically, the fresh iron oxide samples were prepared based on a previous report $[19,20]$. Briefly, as a first step, a low crystalline mesophase is produced via dipcoating in argon atmosphere and stabilization at $250{ }^{\circ} \mathrm{C}$ in air. Calcination in air at $400{ }^{\circ} \mathrm{C}$ for 10 min yields ferrihydrite films $(\mathrm{FH})$ with a well-ordered mesoporous structure and low crystallinity, whereas calcination at $550{ }^{\circ} \mathrm{C}$ for $10 \mathrm{~min}$ forms a highly crystalline hematite film (HEM). Maghemite films (MAGH) are obtained after a heat treatment of the mesophase in $\mathrm{N}_{2}$ at $350{ }^{\circ} \mathrm{C}$ for $5 \mathrm{~h}$. Partial reduced maghemite/magnetite films (MAGH/MAGN) form after a heat treatment in $\mathrm{N}_{2}$ at $400{ }^{\circ} \mathrm{C}$ for $2 \mathrm{~h}$ followed by a reduction in $\mathrm{H}_{2} / \mathrm{Ar}$ at $350{ }^{\circ} \mathrm{C}$ for $1 \mathrm{~h}$.

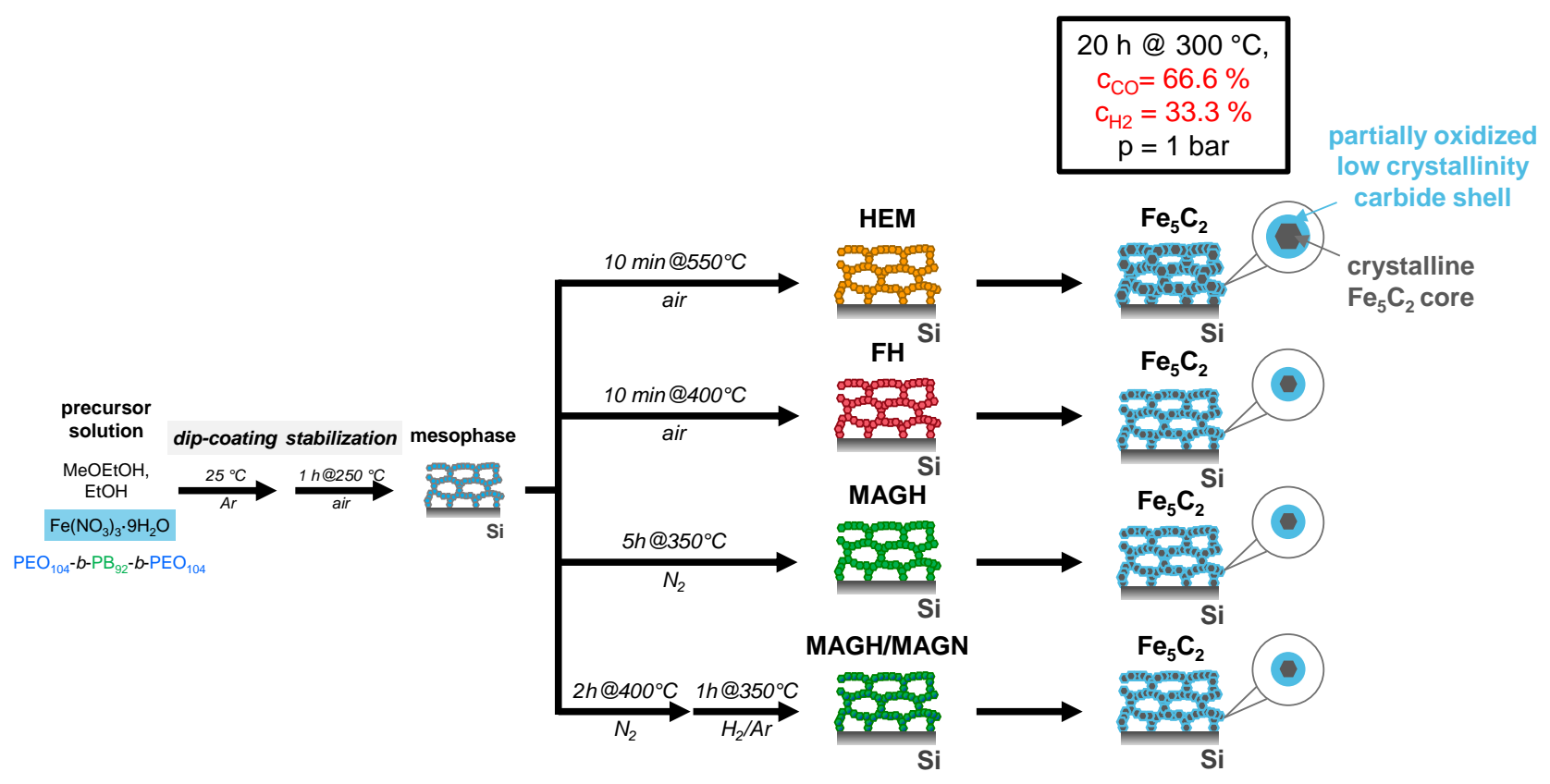

Scheme 1. Synthetic approach for mesoporous iron oxide films with different initial phases and subsequent controlled exposure to syngas atmospheres. The mesophase is obtained after dip-coating and mild calcination at $250{ }^{\circ} \mathrm{C}$. Further thermal treatment enables the formation of different iron oxide phases: air forms HEM, FH; nitrogen forms MAGH which can be partially reduced to MAGH/MAGN. All films were treated in $\mathrm{CO} / \mathrm{H}_{2}$ (2 to 1, 1 bar) for $20 \mathrm{~h}$ at $300^{\circ} \mathrm{C}$ leading to the formation of iron carbides while retaining the mesoporous structure. The carbides appear to consist of core-shell structures with highly crystalline $\mathrm{Fe}_{5} \mathrm{C}_{2}$ cores surrounded by partially oxidized low-crystallinity carbide shell.

In order to study the impact of the phase composition on the carbide formation, all oxide films were exposed to syngas $\left(66 \% \mathrm{CO}, 33 \% \mathrm{H}_{2}\right)$ at $300{ }^{\circ} \mathrm{C}$ for $20 \mathrm{~h}$ at atmospheric pressure. 
In order to study the formation of iron carbides during the aforementioned process, scanning electron microscopy (SEM), transmission electron microscopy (TEM), and selected area electron diffraction (SAED) were performed and presented alongside results from $\mathrm{X}$-ray diffraction measurements in gracing-incidence geometry for the incoming beam (GI-XRD) of the fresh hematite (HEM), ferrihydrite (FH), maghemite (MAGH), and maghemite/magnetite (MAGH/MAGN) films are presented in Figure 1.



Figure 1. Fresh iron oxide films obtained after controlled exposure of the mesophase to different gas atmospheres. $550{ }^{\circ} \mathrm{C}$ air for $10 \mathrm{~min}$ forms (a) $\mathrm{HEM}$ and $400^{\circ} \mathrm{C}$ air for $10 \mathrm{~min}$ (b) $\mathrm{FH} .350{ }^{\circ} \mathrm{C}$ in $\mathrm{N}_{2}$ for $5 \mathrm{~h}$ forms (c) MAGH. $400{ }^{\circ} \mathrm{C}$ in $\mathrm{N}_{2}$ for $2 \mathrm{~h}$ $\rightarrow 350{ }^{\circ} \mathrm{C}$ in $\mathrm{H}_{2} / \mathrm{Ar}$ for $1 \mathrm{~h}$ (d) MAGH/MAGN. All samples were characterized by (I) SEM, (II/III) TEM, (IV) SAED and (V) GI-XRD.

Fresh hematite (HEM) samples (Figure 1a) present a mesoporous-templated film with a grid-like morphology according to SEM imaging (Figure 1(aI)), which can be explained by sintering processes of neighboring crystallites. Such grid-like structures have already been observed in our previous work [21] and for other systems (e.g., $\left.\mathrm{TiO}_{2}, \mathrm{Nb}_{2} \mathrm{O}_{5}\right)[29,30]$. Representative TEM images (Figure 1(aII,III)) reveal partially sintered crystallites and an average pore wall thickness of $11 \pm 3 \mathrm{~nm}$. Compared to the SEM top view images the pore walls appear to be thinner in the bulk indicating a higher degree of sintering on the surface. The recorded SAED pattern can be assigned to hematite (Figure 1(aIV)) and shows only few spots instead of homogeneous diffraction rings observed for polycrystalline materials. These patterns have been recorded for spots larger than $100 \mathrm{~nm}$, indicating crystallites sharing a nearly identical orientation [30]. The GI-XRD pattern (Figure 1(aV)) shows narrow reflections for a pure hematite phase and crystallite size of $18 \mathrm{~nm}$ determined using the Debye-Scherrer equation for the strongest reflection at $2 \theta=33.153^{\circ}$.

Ferrihydrite (FH) precursor films are fine-grained, low crystalline materials with a well-ordered mesoporosity (SEM Figure 1(bI)). The absence of any clear lattice fringes in the corresponding TEM images confirms a low crystallinity (Figure 1(bII,III)), which is further corroborated by SAED analysis (Figure 1(bIV)). Evidently, the SAED pattern only shows signals stemming from the carbon film of the TEM grid. The formation of larger crystallites was ruled out using GI-XRD analysis (Figure 1(bV)). 
Maghemite (MAGH) precursor films feature a well-defined pore structure with a pore diameter of $7 \pm 1 \mathrm{~nm}$ (Figure 1(cI)). Lattice fringes observed in representative TEM images can be assigned to the maghemite phase and the pore walls have an average thickness of $7 \pm 1 \mathrm{~nm}$ (Figure 1(cII,III)). Several rings can be observed in the SAED pattern, which can be assigned to maghemite (Figure 1(cIV)). The GI-XRD pattern (Figure 1(cV)) recorded for maghemite features reflections corresponding to either maghemite or magnetite. Due to the structural similarity of maghemite and magnetite, it is not possible to distinguish between both crystal phases. Using the Scherrer equation for the strongest reflection at $2 \theta$ $=35.7^{\circ}$, an average crystallite size of $7 \mathrm{~nm}$ was determined which correspond well to the wall thickness determined by TEM.

Maghemite films that have been partially transformed into magnetite by reductive treatment (MAGH/MAGN) show signs of grain coarsening and the formation of a gridlike structure (Figure 1(dI)). SAED (Figure 1(dV)) and GI-XRD (Figure 1(dV)) results are similar to the MAGH film. As mentioned above, it is not possible to clearly assign the maghemite or magnetite phase. With $8 \mathrm{~nm}$, a similar value for the average crystallite size can be obtained.

In general, the properties of all precursor films are consistent with results from previously reported studies [19-21].

In order to study the precursor films' tendencies to form carbides, all iron oxide films were treated in $\mathrm{CO} / \mathrm{H}_{2}$ at $300{ }^{\circ} \mathrm{C}$ for $20 \mathrm{~h}$. Figure 2 displays the corresponding (I) SEM, (II, III) TEM, (IV) SAED, and (V) GI-XRD analysis results.
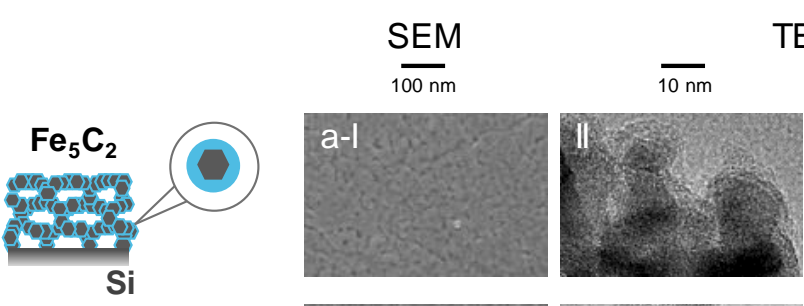

TEM
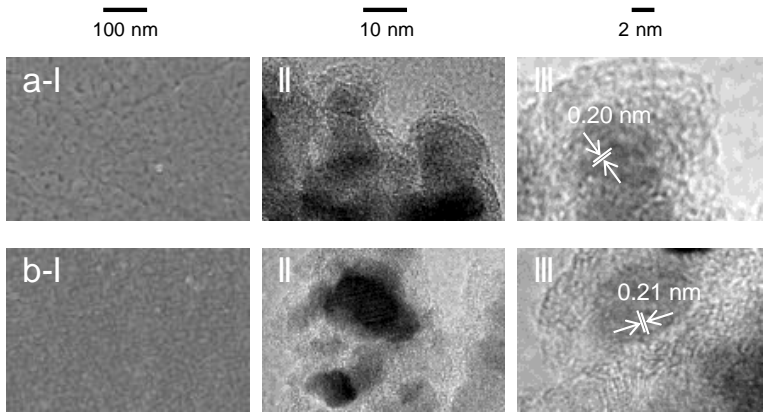

$\mathrm{Si}$



$\mathrm{Si}$



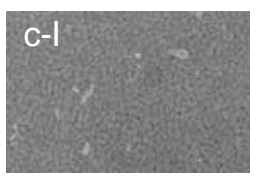

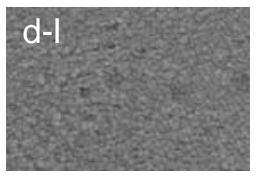

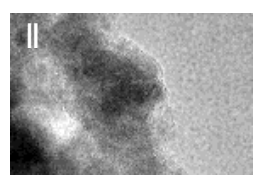



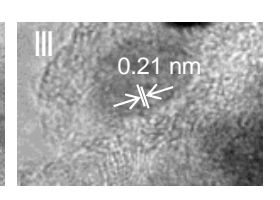

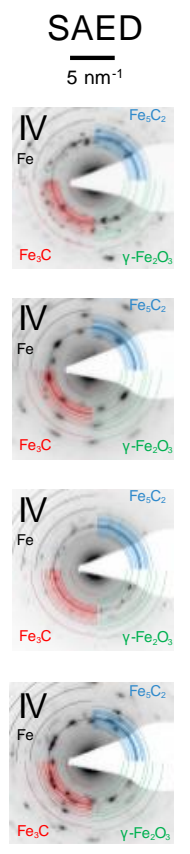

XRD


$\mathrm{Fe}$ - syn (PDF 00-006-0696) $\mathrm{y}-\mathrm{Fe}_{2} \mathrm{O}_{3}\left(\mathrm{PDF}\right.$ 00-032-1346) $\mathrm{Fe}_{3} \mathrm{O}_{4}$ (PDF 00-019-0629) $\alpha-\mathrm{Fe}_{2} \mathrm{O}_{3}$ (PDF-00-033-0664) $\mathrm{Fe}_{3} \mathrm{C}$ (PDF 03-065-2411) $\mathrm{Fe}_{5} \mathrm{C}_{2}$ (PDF 01-089-2544)

Figure 2. Physicochemical analysis for mesoporous iron oxide films after treatment in $\mathrm{CO} / \mathrm{H}_{2}$ (2 to 1 ) flowrate $372 \mathrm{~mL} / \mathrm{min}$ at $300{ }^{\circ} \mathrm{C}$ for $20 \mathrm{~h}$. (a) HEM, (b) FH, (c) MAGH, and (d) MAGH/MAGN. All samples were characterized by (I) SEM, (II/III) TEM, (IV) SAED, and (V) GI-XRD.

HEM precursor films show well-preserved mesopores after the treatment, as evidenced by top-view SEM imaging (Figure 2(aI)). Yet, there are indications for a swelling of the pore walls. TEM images (Figure 2(aII,III)) illustrate the formation of a core-shell structure of the carburized materials. Lattice fringes of $0.20 \mathrm{~nm}$ matching to (510) lattice planes of $\mathrm{Fe}_{5} \mathrm{C}_{2}$ can be observed in the core indicating the full transformation of the initial 
hematite to a carbide phase. The shell appears to consist of a low-crystallinity material with no lattice fringes. Diffraction spots in the SAED pattern (Figure 2(aIV)) are also consistent with the formation of iron carbides. However, assignment of carbides is challenging due to the great number of possible diffraction rings. The GI-XRD pattern (Figure 2(aV)) features three reflections that nicely match to reflections of $\mathrm{Fe}_{5} \mathrm{C}_{2}$. An average crystallite size of 8 $\mathrm{nm}$ can be determined, indicating a significant decrease in crystallite size compared to the corresponding oxide phase.

FH precursor films treated in $\mathrm{CO} / \mathrm{H}_{2}$ feature a grid-like structure (SEM, Figure 2(bI)). Similar to HEM, the analysis via TEM imaging indicates a core-shell structure consisting of a crystalline carbide core (lattice fringes of $0.21 \mathrm{~nm}$ corresponding to (021) lattice planes) with a shell of low crystallinity (TEM, Figure 2(bII,III)). The SAED pattern consists of comparably few diffraction spots (Figure 2(bIV)), indicating domains with crystallites that share a similar orientation. The most intense reflections in the GI-XRD pattern (Figure 2(bV)) indicate the formation of iron carbide with a comparably small average crystallite size of $4 \mathrm{~nm}$.

MAGH films exposed to $\mathrm{CO} / \mathrm{H}_{2}$ still feature a mesoporous structure with pore walls that appear much thicker than in the original oxide film (Figure 2(cI)). TEM analysis shows the formation of a core/shell structure with a carbide core. The shell shows in some areas in the shell with lattice fringes of $0.25 \mathrm{~nm}$, which could either correspond to oxide or carbide phase. SAED (Figure 2(cIV)) and GI-XRD (Figure 2(cV)) both provide clear evidence for the formation of $\mathrm{Fe}_{5} \mathrm{C}_{2}$. The observed average crystallite size of $5 \mathrm{~nm}$ after is smaller than in the original oxide $(7 \mathrm{~nm})$.

SEM images indicate for MAGH/MAGN films after $\mathrm{CO} / \mathrm{H}_{2}$ exposure a similar sintered appearance as for treated FH films (Figure 2d). This material also features a morphology consisting of carbide cores which are surrounded by a shell of low crystallinity (TEM). Again, a small crystallite size of $4 \mathrm{~nm}$ can be calculated (XRD), highlighting the nano-crystallinity of the formed carbide cores.

In brief, the reaction conditions of $300^{\circ} \mathrm{C}$ for $20 \mathrm{~h}$ in a mixture of $\mathrm{CO} / \mathrm{H}_{2}$ with a ratio of 2 to 1 lead to a conversion of all presented precursor films to carbides. Despite the high reduction strength of the syngas atmosphere, the initial soft-templated mesoporous structure is mainly preserved. TEM analyses for HEM and MAGH indicate that crystalline oxide walls transform into carbides with a distinct structure. The formed walls contain crystalline particles, each of them surrounded by a layer of lower crystallinity. Apparently, the oxide crystallites are transformed into a carbidic core-shell structure made up of crystalline cores and low-crystallinity shells. Moreover, exposure of the materials to air appears to induce a partial surface oxidation of the carbide shell. Depending on the initial precursor oxide phase, different degrees of crystallinity can be observed for the carbide films, i.e., a different width of the signals in the GI-XRD patterns (HEM > MAGH/MAGN $>$ MAGH > FH).

Surface-analysis of the $\mathrm{CO} / \mathrm{H}_{2}$-treated HEM, FH, MAGH, and MAGH/MAGN precursor films treated in a mixture of $\mathrm{CO} / \mathrm{H}_{2}$ was performed via XPS (Figure 3). In a typical Fe $2 p$ spectrum, iron carbides usually depict a sharp doublet peak, whose 2p3/2 peak locates at $707.9 \mathrm{eV}$ and a $\mathrm{Fe}-\mathrm{C}$ contribution around $284.1 \mathrm{eV}$ in the $\mathrm{C} 1 \mathrm{~s}$ spectrum [20]. Both contributions can be found in all $\mathrm{CO} / \mathrm{H}_{2}$ treated films, indicating that regardless of the initial iron oxide phase, a significant contribution of a carbide phase in the surface region can be deduced. 
HEM
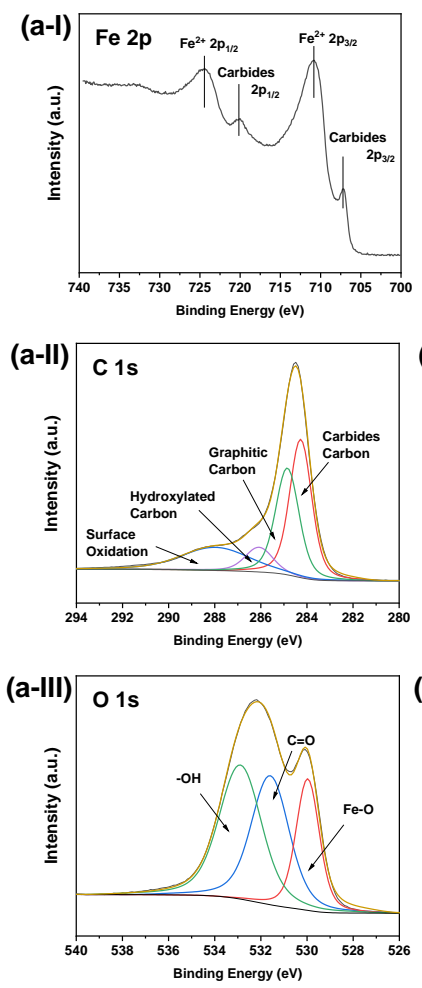

FH
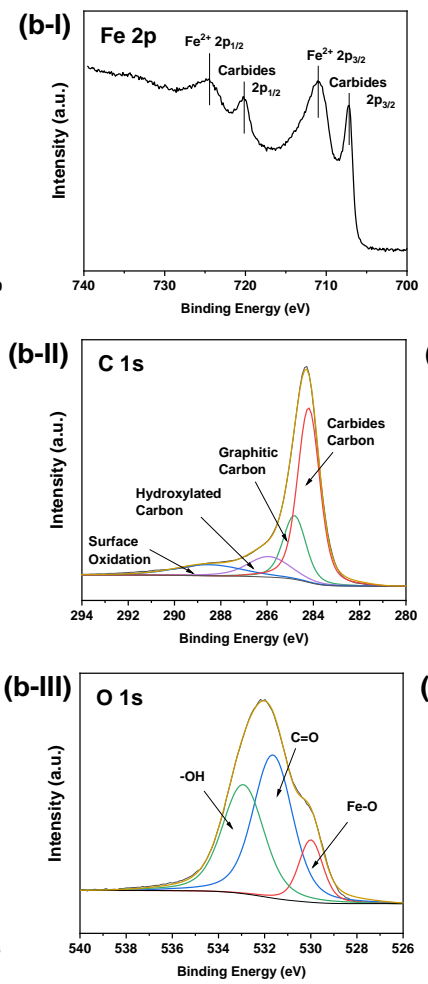

MAGH
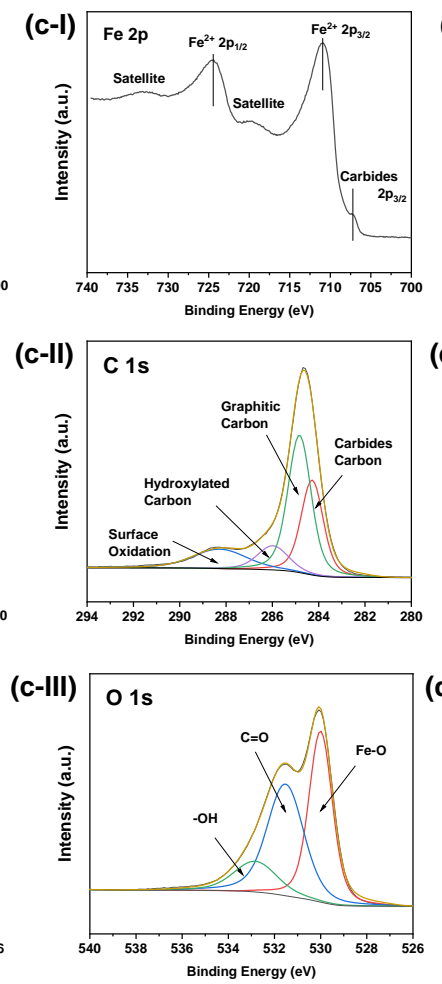

MAGH/MAGN
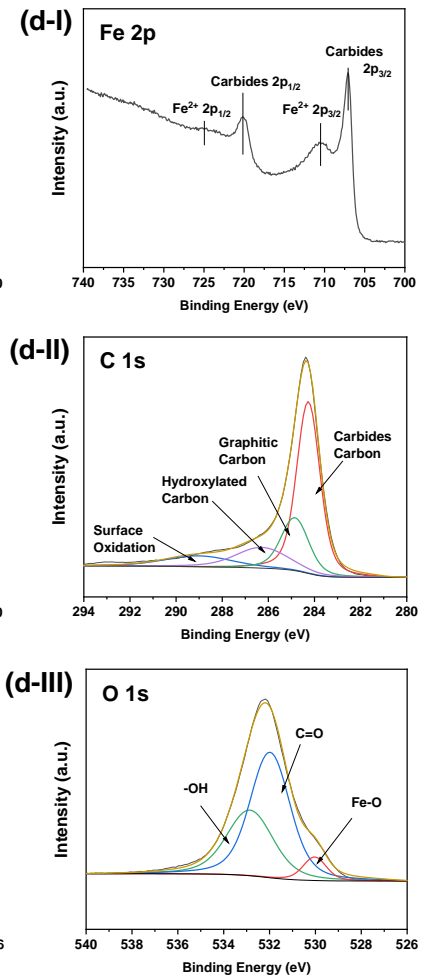

Figure 3. XPS spectra of ((a) I-III HEM), ((b) I-III) FH), ((c) I-III) MAGH), ((d) I-III)) MAGH/MAGN samples after the $\mathrm{CO} / \mathrm{H}_{2}$ syngas treatment.

Among the samples, the carburized MAGH film features a very weak signal for the carbide phase in the corresponding Fe $2 p$ and $C 1$ s spectra. Instead, the main contributions in the Fe $2 p$ spectrum can be assigned to a typical $\mathrm{Fe}^{2+}$ spectrum, with an asymmetric peak located at $710.8 \mathrm{eV}$, and a broad satellite feature at $716.1 \mathrm{eV}$ [31,32]. Meanwhile, a strong $\mathrm{Fe}-\mathrm{O}$ contribution can be found at $529.8 \mathrm{eV}$ in the $\mathrm{O} 1 \mathrm{~s}$ spectrum [33], further supporting that the surface of the $\mathrm{CO} / \mathrm{H}_{2}$-treated MAGH sample is partly oxidized. A similar feature can also be observed in the $\mathrm{CO} / \mathrm{H}_{2}$-treated HEM film. These results suggest the formation of an iron carbide during the treatment, which shows a crystalline core surrounded by a low-crystallinity carbide shell. Due to subsequent exposure of the films to air, the surface of that weakly crystalline shell undergoes partial oxidation. Carburized MAGH/MAGN films also provide evidence for iron carbide species close to the surface, yet with a lower degree of surface oxidation after exposure to air. Similarly, strong iron carbide features can be observed in the carburized FH samples, with relatively weak surface oxidation.

Except for the contributions assigned to iron carbides and iron oxide, several prominent features in the spectra can be assigned to graphitic carbon $(284.8 \mathrm{eV})$, surface hydroxylated carbon $(286.3 \mathrm{eV})$ and surface oxidation $(298.1 \mathrm{eV})$ in every $\mathrm{C} 1 \mathrm{~s}$ spectra [34,35]. In the $\mathrm{O} 1 \mathrm{~s}$ spectrum, two peaks assignable to $\mathrm{C}-\mathrm{O}(531.9 \mathrm{eV})$ and $-\mathrm{OH}(533.1 \mathrm{eV})$ can be observed and are well-known from other iron oxide materials [36]. These peaks originate from the inevitable adventitious carbon species adsorbed on the material's surface or from the surface oxidation caused by exposure to air. It should be noted that these peaks do not correlate with the chemical structure of the bulk material of the films [37].

The study presents a simple approach for the synthesis of ordered mesoporous iron carbide films using iron oxide precursor films of different phase, composition and crystallinity, yet with similar morphology. By a carburization reaction under rather mild conditions, i.e., $300{ }^{\circ} \mathrm{C}, 20 \mathrm{~h}, \mathrm{CO} / \mathrm{H}_{2}$ (ratio of 2/1), a bulk conversion to the $\mathrm{Fe}_{5} \mathrm{C}_{2}$ carbide phase can be achieved, independent of the initial bulk phase or composition of the precursor films. Due 
to the mild conditions in the carburization step, the mesoporous structure is kept intact for all films.

Accordingly, the initial phase and composition of different iron oxides do not significantly affect the preferred reaction product. Yet, initial crystallite sizes affect the grain size of the formed carbide. For instance, HEM shows the biggest crystallite sizes prior to and after $\mathrm{CO} / \mathrm{H}_{2}$ treatment compared to the other materials. Moreover, we observed the formation of a low-crystallinity shell with only a few lattice fringes that can be assigned to either iron carbides or oxides.

Core-shell structures have been observed in previous studies for catalysts with a carbide phase, where the presence of an oxide shell has been related to air exposure prior to sample analysis [38-40]. From our findings, we propose a structure of highly crystalline iron carbide cores surrounded by a thin shell of partially surface-oxidized, weakly crystalline carbide. In this context, signals for both oxidic and carbidic species can be detected in the XPS spectra, indicating a partially oxidized carbide shell that, most likely, results from exposure to air after carburization. Depending on the initial phase, a different degree of surface oxidation can be detected. Overall, the phase assignment proofs to be difficult for the observed shell due to its low crystallinity and limitations of the employed methods with respect to the analysis of iron-carbon compounds.

\section{Conclusions}

In summary, soft-templated mesoporous iron oxide films with different oxidation states and phase composition were successfully transformed into iron carbides. Under the chosen conditions $\left(300{ }^{\circ} \mathrm{C}, 20 \mathrm{~h}, \mathrm{CO} / \mathrm{H}_{2} 2\right.$ to 1$)$ all samples form carbides independent of the initial oxide phase. SAED patterns indicate a local ordering of crystallites. We propose the formation of carbide phases with core-shell structure, in which the core consists of a crystalline carbide and the shell consists of a low-crystallinity partially surface-oxidized carbide. The degree of oxidation appears to depend on the initial phase composition. Swelling of the structure observed in the top view SEM is most likely the results of the formed low-crystallinity carbide shell. However, other methods are required to fully resolve the phase information of the shell.

This work reveals the phase transformation of iron oxides to iron carbides with different initial phase compositions into carbides upon controlled exposure to syngas atmospheres, leading the field one step further towards understanding the intermediate phase transformation of during the complicated $\mathrm{CO}_{2}-\mathrm{FT}$ reaction.

\section{Materials and Methods}

For this study a selection of iron oxide films have been prepared with different oxidation degree by controlled thermal treatment of a stabilized mesophase obtained by dip coating on silicon substrates.

Iron nitrate nonahydrate from $(99+\%)$ was purchased from Acros Organics (Acros Organics, Fair Lawn, NJ, USA), Ethanol ( $99.9+\%$, ACS grade) was obtained from VWR (Radnor, PA, USA). 2-Methoxyethanol (99.3+\%, ACS grade) was obtained from Alfa Aesar (Alfa Aesar, Haverhill, MA, USA). The soft template was a copolymer $\left(\mathrm{PEO}_{104}-b-\mathrm{PB}_{92}-b-\right.$ $\mathrm{PEO}_{104}$ ) was synthesized by Polymer Service GmbH Merseburg (Polymer Service GmbH, Merseburg, Germany) [24]. All chemicals were used without further purification.

The stabilized mesophase was prepared analogue to previous works [19]. Adapted from Brezesinski at al. [41], a dip coating solution was prepared by dissolving $\mathrm{PEO}_{104}-b$ $\mathrm{PB}_{92}-b-\mathrm{PEO}_{104}(109 \mathrm{mg})$ in a mixture of ethanol $(4.36 \mathrm{~mL})$ and 2-methoxyethanol $(4.64 \mathrm{~mL})$ for $20 \mathrm{~min}$ at $40{ }^{\circ} \mathrm{C}$ yielding a colorless solution. $\mathrm{Fe}\left(\mathrm{NO}_{3}\right)_{3} \cdot 9 \mathrm{H}_{2} \mathrm{O}(1173 \mathrm{mg})$ was added and stirred for an additional hour resulting in a solution with orange-red color. $\mathrm{Si}(100)$-wafers were used as substrate.

Film deposition and thermal treatment were similar to previous works $[19,20]$. An essential step during film synthesis is a controlled low humidity that can be ensured in a glove box with an argon atmosphere. Substrates were dip coated with a withdrawal rate of 
$400 \mathrm{~mm} / \mathrm{min}$ and dried in argon for $10 \mathrm{~min}$. Afterwards, the films were transferred under inert conditions into an oven and calcined at $250{ }^{\circ} \mathrm{C}$ in air for $1 \mathrm{~h}$ forming the mesophase. Calcination of the mesophase at $400{ }^{\circ} \mathrm{C}$ for $10 \mathrm{~min}$ in air forms $\mathrm{FH}$, at $550{ }^{\circ} \mathrm{C}$ for $10 \mathrm{~min}$ HEM as reported in earlier studies $[19,21]$. Treatment in nitrogen for $5 \mathrm{~h}$ at $350^{\circ} \mathrm{C}$ forms MAGH, whereas treatment at $400{ }^{\circ} \mathrm{C}$ in nitrogen for $2 \mathrm{~h}$ and subsequent treatment in $\mathrm{H}_{2}$ $(4 \%) / \mathrm{Ar}$ at $350^{\circ} \mathrm{C}$ for $1 \mathrm{~h}$ forms a partially reduced MAGH/MAGN phase [20].

For the $\mathrm{CO} / \mathrm{H}_{2}$ experiments $\mathrm{HEM}, \mathrm{FH}, \mathrm{MAGH}$, and MAGH/MAGN films were wrapped in quartz wool and placed in a tube reactor. The reactor was first flushed with $\mathrm{He}$ ( $372 \mathrm{~mL} / \mathrm{min})$ for $1 \mathrm{~h}$ and then in $\mathrm{CO}(248 \mathrm{~mL} / \mathrm{min})$ and $\mathrm{H}_{2}(124 \mathrm{~mL} / \mathrm{min})$ for an additional hour. Thereafter, the samples were heated to $300{ }^{\circ} \mathrm{C}$ with $10 \mathrm{~K} / \mathrm{min}$ and kept at $300{ }^{\circ} \mathrm{C}$ for $20 \mathrm{~h}$. The samples were then cooled down in $\mathrm{CO} / \mathrm{H}_{2}$ to $80^{\circ} \mathrm{C}$ in a time frame of $1.5 \mathrm{~h}$ followed by a change of the gas feed to $\mathrm{He}(372 \mathrm{~mL} / \mathrm{min})$. The samples were removed after a cool down in $\mathrm{He}$ to $50^{\circ} \mathrm{C}$.

TEM analysis was conducted on a Tecnai G 220 S-TWIN (FEI, Hilsboro, OR, USA) instrument that was operated at $200 \mathrm{kV}$. The films were scraped off from the substrates transferred onto copper grids coated with a carbon-film. Before installment of the samples a second copper grid with a carbon film placed on top to ensure that no material can escape the sample holder. To ensure that no sample SAED was performed on the same instrument using an aperture resulting in an investigated sample area with a diameter of $180 \mathrm{~nm}$.

SEM imaging was performed using a JEOL 7401F (JEOL, Tokyo, Japan) instrument at an acceleration voltage of $10 \mathrm{kV}$ and a working distance of approximately $4.5 \mathrm{~mm}$. ImageJ (National Institutes of Health, Bethesda, MD, USA) was employed to analyze the SEM images [42].

XRD was measured on a Bruker D8 Advance instrument $(\mathrm{Cu} \mathrm{K} / \alpha$ radiation, $\lambda=1.5409 \AA)$ with a grazing incident beam $\left(1^{\circ}\right)$. Reflections were assigned using PDFMaintEx library version 9.0.133 (Bruker, Billerica, MA, USA). Crystallite sizes were estimated by applying the Scherrer equation to the most intense signal ((104)-reflection).

XPS spectra were obtained via Thermo Fisher Scientific ESCALAB 250Xi (Thermo Fischer Scientific, Waltham, MA, USA), with the spot size $400 \mu \mathrm{m}$. Avantage was used as XPS data processing software. Shirley background was used with an additional constraint that the background intensity does not exceed the data at any point in the region. Samples were measured as-is, i.e., without removing the $\mathrm{Si}$ substrates. Only minor contributions from the Si substrate $(<2 \%)$ were detected in the spectra.

Author Contributions: A.A. and M.G. contributed to experimental aspects of data analysis, evaluation, and interpretation. A.A. and M.-Y.Y. both contributed to the writing and editing of manuscript. M.-Y.Y. performed XPS measurements and interpretation of the acquired data. M.F. contributed to the XRD measurements and interpretation of the acquired data. R.K. and M.-Y.Y. conceived the study, contributed to the writing and editing of the manuscript. All authors have read and agreed to the published version of the manuscript.

Funding: Aleks Arinchtein and Ralph Kraehnert greatly acknowledge the generous fund of the SPP2080 under the DFG-Project 406695057. Marvin Frisch and Meng-Yang Ye appreciate financial support via BMBF ATO-KAT (03EK3052A).

Data Availability Statement: Original data are available from the authors upon request.

Acknowledgments: The authors thank ZELMI (TU Berlin) for access to TEM analysis.

Conflicts of Interest: The authors declare no conflict of interest.

\section{References}

1. Anderson, T.R.; Hawkins, E.; Jones, P.D. $\mathrm{CO}_{2}$, the greenhouse effect and global warming: From the pioneering work of Arrhenius and Callendar to today's Earth System Models. Endeavour 2016, 40, 178-187. [CrossRef] [PubMed]

2. Peters, G.P.; Andrew, R.M.; Canadell, J.G.; Friedlingstein, P.; Jackson, R.B.; Korsbakken, J.I.; le Quéré, C.; Peregon, A. Carbon dioxide emissions continue to grow amidst slowly emerging climate policies. Nat. Clim. Chang. 2020, 10, 3-6. [CrossRef]

3. Kemper, J. Biomass and carbon dioxide capture and storage: A review. Int. J. Greenh. Gas Control 2015, 40, 401-430. [CrossRef] 
4. Gulzar, A.; Gulzar, A.; Ansari, M.B.; He, F.; Gai, S.; Yang, P. Carbon dioxide utilization: A paradigm shift with $\mathrm{CO}_{2}$ economy. Chem. Eng. J. Adv. 2020, 3, 100013. [CrossRef]

5. Schoedel, A.; Ji, Z.; Yaghi, O.M. The role of metal-organic frameworks in a carbon-neutral energy cycle. Nat. Energy 2016, 1, 16034. [CrossRef]

6. Jiang, X.; Nie, X.; Guo, X.; Song, C.; Chen, J.G. Recent Advances in Carbon Dioxide Hydrogenation to Methanol via Heterogeneous Catalysis. Chem. Rev. 2020, 120, 7984-8034. [CrossRef]

7. Kondratenko, E.V.; Mul, G.; Baltrusaitis, J.; Larrazábal, G.O.; Pérez-Ramírez, J. Status and perspectives of $\mathrm{CO}_{2}$ conversion into fuels and chemicals by catalytic, photocatalytic and electrocatalytic processes. Energy Environ. Sci. 2013, 6, 3112. [CrossRef]

8. Skrypnik, A.S.; Yang, Q.; Matvienko, A.A.; Bychkov, V.Y.; Tulenin, Y.P.; Lund, H.; Petrov, S.A.; Kraehnert, R.; Arinchtein, A.; Weiss, J.; et al. Understanding reaction-induced restructuring of well-defined $\mathrm{Fe}_{\mathrm{x}} \mathrm{O}_{\mathrm{y}} \mathrm{C}_{\mathrm{z}}$ compositions and its effect on $\mathrm{CO}_{2}$ hydrogenation. Appl. Catal. B Environ. 2021, 291, 120121. [CrossRef]

9. Herranz, T.; Rojas, S.; Pérez-Alonso, F.J.; Ojeda, M.; Terreros, P.; Fierro, J.L.G. Genesis of iron carbides and their role in the synthesis of hydrocarbons from synthesis gas. J. Catal. 2006, 243, 199-211. [CrossRef]

10. Ding, M.; Yang, Y.; Xu, J.; Tao, Z.; Wang, H.; Wang, H.; Xiang, H.; Li, Y. Effect of reduction pressure on precipitated potassium promoted iron-manganese catalyst for Fischer-Tropsch synthesis. Appl. Catal. A Gen. 2008, 345, 176-184. [CrossRef]

11. De Smit, E.; Weckhuysen, B.M. The renaissance of iron-based Fischer-Tropsch synthesis: On the multifaceted catalyst deactivation behaviour. Chem. Soc. Rev. 2008, 37, 2758-2781. [CrossRef] [PubMed]

12. Tian, Z.; Wang, C.; Yue, J.; Zhang, X.; Ma, L. Effect of a potassium promoter on the Fischer-Tropsch synthesis of light olefins over iron carbide catalysts encapsulated in graphene-like carbon. Catal. Sci. Technol. 2019, 9, 2728-2741. [CrossRef]

13. Shroff, M.D.; Kalakkad, D.S.; Coulter, K.E.; Kohler, S.D.; Harrington, M.S.; Jackson, N.B.; Sault, A.G.; Datye, A.K. Activation of Precipitated Iron Fischer-Tropsch Synthesis Catalysts. J. Catal. 1995, 156, 185-207. [CrossRef]

14. Yao, B.; Xiao, T.; Makgae, O.A.; Jie, X.; Gonzalez-Cortes, S.; Guan, S.; Kirkland, A.I.; Dilworth, J.R.; Al-Megren, H.A.; Alshihri, S.M.; et al. Transforming carbon dioxide into jet fuel using an organic combustion-synthesized Fe-Mn-K catalyst. Nat. Commun. 2020, 11, 6395. [CrossRef]

15. Galvis, H.M.T.; Bitter, J.H.; Davidian, T.; Ruitenbeek, M.; Dugulan, A.I.; de Jong, K.P. Iron Particle Size Effects for Direct Production of Lower Olefins from Synthesis Gas. J. Am. Chem. Soc. 2012, 134, 16207-16215. [CrossRef] [PubMed]

16. Petersen, M.A.; Cariem, M.J.; Claeys, M.; van Steen, E. A DFT perspective of potassium promotion of $\chi-\mathrm{Fe}_{5} \mathrm{C}_{2}(100)$. Appl. Catal. A Gen. 2015, 496, 64-72. [CrossRef]

17. Galvis, H.M.T.; Koeken, A.C.J.; Bitter, J.H.; Davidian, T.; Ruitenbeek, M.; Dugulan, A.I.; de Jong, K.P. Effects of sodium and sulfur on catalytic performance of supported iron catalysts for the Fischer-Tropsch synthesis of lower olefins. J. Catal. 2013, 303, 22-30. [CrossRef]

18. Davis, B.H. Fischer-Tropsch synthesis: Current mechanism and futuristic needs. Fuel Process. Technol. 2001, 71, 157-166. [CrossRef]

19. Schulz, K.; Schmack, R.; Klemm, H.W.; Kabelitz, A.; Schmidt, T.; Emmerling, F.; Kraehnert, R. Mechanism and kinetics of hematite crystallization in air: Linking bulk and surface models via mesoporous films with defined nanostructure. Chem. Mater. 2017, 29, 1724-1734. [CrossRef]

20. Kraffert, K.; Kabelitz, A.; Siemensmeyer, K.; Schmack, R.; Bernsmeier, D.; Emmerling, F.; Kraehnert, R. Nanocasting of Superparamagnetic Iron Oxide Films with Ordered Mesoporosity. Adv. Mater. Interfaces 2018, 5, 1700960. [CrossRef]

21. Arinchtein, A.; Schmack, R.; Kraffert, K.; Radnik, J.; Dietrich, P.; Sachse, R.; Kraehnert, R. Role of Water in Phase Transformations and Crystallization of Ferrihydrite and Hematite. ACS Appl. Mater. Interfaces 2020, 12, 38714-38722. [CrossRef] [PubMed]

22. Grosso, D.; Cagnol, F.; Soler-Illia, G.J.d.A.; Crepaldi, E.L.; Amenitsch, H.; Brunet-Bruneau, A.; Bourgeois, A.; Sanchez, C. Fundamentals of Mesostructuring through Evaporation-Induced Self-Assembly. Adv. Funct. Mater. 2004, 14, 309-322. [CrossRef]

23. Yan, M.; Henderson, M.J.; Gibaud, A. Grating induced micelle alignment of mesostructured silica films. Appl. Phys. Lett. 2007, 91, 023104. [CrossRef]

24. Strasser, P.; Polte, J.; Kraehnert, R.; Görke, O.; Ortel, E.; Bernsmeier, D.; Eckhardt, B. Micelle-Templated Mesoporous Films of Magnesium Carbonate and Magnesium Oxide. Adv. Mater. 2012, 24, 3115-3119.

25. Frisch, M.; Laun, J.; Marquardt, J.; Arinchtein, A.; Bauerfeind, K.; Bernsmeier, D.; Bernicke, M.; Bredow, T.; Kraehnert, R. Bridging experiment and theory: Enhancing the electrical conductivities of soft-templated niobium-doped mesoporous titania films. Phys. Chem. Chem. Phys. 2021, 23, 3219-3224. [CrossRef]

26. Brezesinski, T.; Fattakhova Rohlfing, D.; Sallard, S.; Antonietti, M.; Smarsly, B.M. Highly Crystalline $\mathrm{WO}_{3}$ Thin Films with Ordered 3D Mesoporosity and Improved Electrochromic Performance. Small 2006, 2, 1203-1211. [CrossRef] [PubMed]

27. Bernicke, M.; Eckhardt, B.; Lippitz, A.; Ortel, E.; Bernsmeier, D.; Schmack, R.; Kraehnert, R. Synthesis and OER activity of NiO coatings with micelle-templated mesopore structure. ChemistrySelect 2016, 1, 482-489. [CrossRef]

28. Bernsmeier, D.; Ortel, E.; Polte, J.; Eckhardt, B.; Nowag, S.; Haag, R.; Kraehnert, R. Versatile control over size and spacing of small mesopores in metal oxide films and catalytic coatings via templating with hyperbranched core-multishell polymers. J. Mater. Chem. A 2014, 2, 13075-13082. [CrossRef]

29. Sakatani, Y.; Grosso, D.; Nicole, L.; Boissière, C.; Soler-Illia, G.J.D.A.A.; Sanchez, C. Optimised photocatalytic activity of grid-like mesoporous $\mathrm{TiO}_{2}$ films: Effect of crystallinity, pore size distribution, and pore accessibility. J. Mater. Chem. 2006, 16, 77-82. 
30. Brezesinski, T.; Groenewolt, M.; Pinna, N.; Amenitsch, H.; Antonietti, M.; Smarsly, B. Surfactant-Mediated Generation of Iso-Oriented Dense and Mesoporous Crystalline Metal-Oxide Layers. Adv. Mater. 2006, 18, 1827-1831. [CrossRef]

31. Lv, H.; Zhao, H.; Cao, T.; Qian, L.; Wang, Y.; Zhao, G. Efficient degradation of high concentration azo-dye wastewater by heterogeneous Fenton process with iron-based metal-organic framework. J. Mol. Catal. A Chem. 2015, 400, 81-89. [CrossRef]

32. Grosvenor, A.P.; Kobe, B.A.; Biesinger, M.C.; McIntyre, N.S. Investigation of multiplet splitting of Fe 2p XPS spectra and bonding in iron compounds. Surf. Interface Anal. 2004, 36, 1564-1574. [CrossRef]

33. Wang, W.; Niu, Q.; Zeng, G.; Zhang, C.; Huang, D.; Shao, B.; Zhou, C.; Yang, Y.; Liu, Y.; Guo, H.; et al. 1D porous tubular g-C $3 N_{4}$ capture black phosphorus quantum dots as 1D/0D metal-free photocatalysts for oxytetracycline hydrochloride degradation and hexavalent chromium reduction. Appl. Catal. B Environ. 2020, 273, 119051. [CrossRef]

34. Gupta, A.; Mittal, M.; Singh, M.K.; Suib, S.L.; Pandey, O.P. Low temperature synthesis of NbC/C nano-composites as visible light photoactive catalyst. Sci. Rep. 2018, 8, 1-17. [CrossRef]

35. Bourlier, Y.; Bouttemy, M.; Patard, O.; Gamarra, P.; Piotrowicz, S.; Vigneron, J.; Aubry, R.; Delage, S.; Etcheberry, A. Investigation of InAIN Layers Surface Reactivity after Thermal Annealings: A Complete XPS Study for HEMT. ECS J. Solid State Sci. Technol. 2018, 7, P329-P338. [CrossRef]

36. Kwan, Y.C.G.; Ng, G.M.; Huan, C.H.A. Identification of functional groups and determination of carboxyl formation temperature in graphene oxide using the XPS O 1s spectrum. Thin Solid Films 2015, 590, 40-48. [CrossRef]

37. Miller, D.J.; Biesinger, M.C.; McIntyre, N.S. Interactions of $\mathrm{CO}_{2}$ and $\mathrm{CO}$ at fractional atmosphere pressures with iron and iron oxide surfaces: One possible mechanism for surface contamination? Surf. Interface Anal. 2002, 33, 299-305. [CrossRef]

38. Oschatz, M.; Krans, N.; Xie, J.; de Jong, K.P. Systematic variation of the sodium/sulfur promoter content on carbon-supported iron catalysts for the Fischer-Tropsch to olefins reaction. J. Energy Chem. 2016, 25, 985-993. [CrossRef]

39. Janbroers, S.; Louwen, J.N.; Zandbergen, H.W.; Kooyman, P.J. Insights into the nature of iron-based Fischer-Tropsch catalysts from quasi in situ TEM-EELS and XRD. J. Catal. 2009, 268, 235-242. [CrossRef]

40. Shroff, M.D.; Datye, A.K. The importance of passivation in the study of iron Fischer-Tropsch catalysts. Catal. Lett. 1996, 37, 101-106. [CrossRef]

41. Brezesinski, K.; Haetge, J.; Wang, J.; Mascotto, S.; Reitz, C.; Rein, A.; Tolbert, S.H.; Perlich, J.; Dunn, B.; Brezesinski, T. Ordered Mesoporous $\alpha-\mathrm{Fe}_{2} \mathrm{O}_{3}$ (Hematite) Thin-Film Electrodes for Application in High Rate Rechargeable Lithium Batteries. Small 2011, 7, 407-414. [CrossRef] [PubMed]

42. Schneider, C.A.; Rasband, W.S.; Eliceiri, K.W. NIH Image to ImageJ: 25 years of image analysis. Nat. Methods 2012, 9, 671-675. [CrossRef] 